\title{
Functional characterization of a neuropeptide receptor exogenously expressed in Aplysia neurons
}

Guo Zhang ${ }^{1 *}$, Shi-Qi Guo ${ }^{*}$, Si-Yuan Yin ${ }^{1 *}$, Wang-Ding Yuan ${ }^{1 *}$, Ping Chen ${ }^{1}$, Ji-Il Kim², Hui-Ying

Wang ${ }^{1}$, Hai-Bo Zhou ${ }^{3,4}$, Abraham J. Susswein ${ }^{5}$, Bong-Kiun Kaang ${ }^{2}$, Jian Jing ${ }^{1,4,6} †$

1 State Key Laboratory of Pharmaceutical Biotechnology, Institute for Brain Sciences, School of Life Sciences, Nanjing University, Nanjing, Jiangsu 210023, China.

2 School of Biological Sciences, Seoul National University, 1, Gwanak-ro, Gwanak-gu, Seoul, 08826, Korea.

3 School of Electronic Science and Engineering, Nanjing University, Nanjing, Jiangsu 210023,

China

4 Peng Cheng Laboratory, Shenzhen 518000, China.

5 The Mina and Everard Goodman Faculty of Life Sciences, Bar Ilan University, Ramat Gan 52900, Israel

6 Department of Neuroscience, Icahn School of Medicine at Mount Sinai, New York, NY 10029, USA.

*These authors contributed equally to this work.

† Corresponding author. Email: jingj01@live.com 


\section{Abstract}

Neuropeptides act mostly on a class of G-protein coupled receptors, and play a fundamental role in the functions of neural circuits underlying behaviors. However, the functions of neuropeptide receptors are poorly understood. Here, we used the mollusc model system Aplysia and microinjected the exogenous neuropeptide receptor apATRPR (Aplysia Allatotropin-related peptide receptor) with an expression vector (pNEX3) into Aplysia neurons that did not express the receptor. Physiological experiments demonstrated that apATRPR could mediate the excitability increase activated by its ligand, apATRP (Aplysia Allatotropin-related peptide), in the Aplysia neurons that now express the receptor. This study provides the first definitive evidence for a physiological function of a neuropeptide receptor in molluscan animals. 


\section{Introduction}

Neuropeptides are the most diverse class of neurotransmitters/neuromodulators, which mostly act on G-protein coupled receptors (GPCRs). The diversity arises in part from the possibility that a single neuropeptide precursor can generate multiple forms of active peptides, and a peptide can act on multiple GPCRs, which in turn might function through different signaling pathways [1, 2]. Consequently, it has been challenging to study peptide signaling systems in vertebrates. Thus, relatively simple model systems, such as Aplysia [3-28], with identifiable neurons in well-defined neural circuits $[3-10,12,14-17,21,22,24-36]$ have been used in these studies. Earlier studies in model systems have focused on identifying neuropeptides and their bioactivity [2, 34, 35, 37-47]. Recently, growing genetic information in model systems is becoming available and has facilitated studying of both neuropeptides and their receptors [36, 48-52]. In the latter studies [49, 50], a common approach is to express putative GPCRs in a cell line, and test activity of potential ligands on the receptor. Then the receptor expression in the CNS and physiological and/or circuit activity of the ligands are demonstrated. If the receptor activity of the ligands in the cell line matches their physiological activity in the CNS, it is used as evidence that the receptor functions in the CNS. However, given that a peptide might act on multiple receptors, it is necessary to demonstrate that the identified GPCR actually displays the proper physiological activity in native neurons. In this paper, we have used an expression vector [3-5], to develop a method that expresses a peptide GPCR in native Aplysia neurons, and examine whether the GPCR could show a physiological activity. Our research utilizes Aplysia allatotropin (apATRP) [39] and its receptor apATRPR [50] as an example.

The neuropeptide allatotropin was first found in tissues of corpora allata in the insect Manduca Sexta, and it stimulated the secretion of juvenile hormone [53]. Subsequently, Allatotropin-related 
peptides have been characterized in animals across phyla, including Arthropoda [54], Annelida [48] and Mollusca [39] with multiple functions in different behaviors, including feeding. The allatotropin receptor was originally characterized in Bombyx mori [55], followed by more insect allatotropin receptors, such as in Aedes aegypti [56] and Tribolium castaneum [57]. Additionally, two allatotropin receptors in the annelid Platynereis [48] and one in Aplysia [50] were characterized. Interestingly, although allatotropin in the protostomes and orexin/hypocretin in vertebrates/deuterostomes [58] display no obvious similarity other than the amidated C-terminal, recent work has shown that their receptors are orthologous to each other based on phylogenetic analyses, supporting the evolutionary homology of allatotropin and orexin signaling systems [59, $60]$.

In Aplysia, apATRP (GFRLNSASRVAHGY-NH2) functions in the feeding network have been extensively characterized. apATRP targets B61/B62 motor neurons in the buccal ganglia by enhancing their excitability [39]. B61/B62 is a site of plasticity after learning that food is inedible [26]. Recently, several ligands, including apATRP, were found to activate apATRPR in CHO-K1 cells transiently transfected with apATRPR. Importantly, the pattern of activations of these ligands in the cell line matches their actions on B61/62 excitability, suggesting that apATRPR likely functions in the Aplysia CNS [50]. However, it is unknown whether apATRPR mediates the excitability increase in native Aplysia neurons. This is a critical question, given that there might be multiple apATRP receptors in Aplysia. Here, we sought to determine whether apATRP is sufficient to mediate the ligand effect on native neurons by evaluating the ability of apATRP to activate apATRPR in Aplysia neurons that do not originally express apATRPR.

To express apATRPR in neurons, we used a plasmid vector, pNEX (plasmid for neuronal 
expression), which is a reliable and effective method to express exogenous proteins in cultured Aplysia neurons [5, 61]. Initially, pNEX was constructed with the AK01a gene (shaker $\mathrm{K}^{+}$channel), and microinjected into Aplysia neurons, which demonstrated that the AK01a channel could modulate the firing of the injected neuron and regulate synaptic interactions [61]. Subsequent studies used pNEX to overexpress the target proteins and elucidated molecular mechanisms of synaptic plasticity [62-68]. Notably, small molecule neurotransmitter receptors (1a metabotropic glutamate receptor [69]) and biogenic amine receptors (octopamine receptor) [64]), which are G-protein coupled receptors, were also expressed in Aplysia neurons through the vector pNEX. However, to date, no studies have applied this technique to neuropeptide GPCRs. Here, we used pNEX3 to successfully express apATRPR in Aplysia neurons that originally did not respond to ATRP. After expression, the neurons showed excitability increase in response to apATRP, indicating that apATRPR can mediate the excitability increase.

\section{Materials and methods}

\section{Construction of plasmids}

pNEX has two members, pNEX $\delta[3,62,63,66,70-74]$ or pNEX3 $[5,67-69,75,76]$. There are eight more enhancers in pNEX3 than pNEX $\delta$, making pNEX3 more effective in expressing a gene [5]. We chose to use pNEX3. Previously, plasmid vectors expressing the pNEX3 gene were constructed in Aplysia neurons [3, 5], and overexpressed proteins in a specific neuron [3, 77, 78]. The plasmid pNEX3-EGFP was derived from the earlier work [73], and the plasmid pcDNA3.1apATRPR was a gift from Dr. Checco at the University of Illinois. To generate the expression plasmid pNEX3- apATRPR, the apATRPR gene was ligated with the vector pNEX3. First, the EGFP gene was digested from the BamHI-KpnI restriction fragment of pNEX3 and separated by agarose 
gel electrophoresis. Second, the apATRPR gene was added to the restriction sites of BamHI and KpnI at the 5' and 3' ends (forward primer: CGCGGATCCATGGGGTCGAACGATACATTC; reverse primer: GGGGTACCTCAGATGCTGGCGAGAGTGACCTC), respectively, by performing polymerase chain reaction (PCR) with the pcDNA3.1-apATRPR plasmid as the template. Then, the target gene, apATRPR, and the vector, pNEX3, were ligated using T4 DNA ligase. All plasmid DNAs used in microinjection were prepared by a standard maxi-prep procedure using an EndoFree Maxi Plasmid Kit.

\section{Electrophysiology}

Aplysia californica (100-300 g) were purchased from Marinus Scientific (Long Beach, CA). Aplysia are hermaphroditic (i.e., each animal has functioning male and female reproductive organs). Animals were kept in an aquarium containing aerated and filtered artificial seawater (Instant Ocean, Aquarium Systems Inc., Mentor, $\mathrm{OH}$ ) at $14-16^{\circ} \mathrm{C}$. The animal room was equipped with a $24 \mathrm{~h}$ light-dark cycle with a light period from 6:00 am to 6:00 pm. Prior to dissection, animals were anesthetized by injection of isotonic $333 \mathrm{mM} \mathrm{MgCl}$ (approximately $50 \%$ of body weight) into the body cavity. All reagents were purchased from Sigma-Aldrich (St. Louis, MO) unless otherwise indicated. apATRP was synthesized by ChinaPeptides Co., Ltd.

Electrophysiological techniques were utilized as described previously [24, 25, 27, 33-35, 43, 45]. Briefly, ganglia were desheathed, transferred to a recording chamber containing $1.5 \mathrm{~mL}$ of artificial seawater (ASW, $460 \mathrm{mM} \mathrm{NaCl}, 10 \mathrm{mM} \mathrm{KCl}, 11 \mathrm{mM} \mathrm{CaCl}_{2}, 55 \mathrm{mM} \mathrm{MgCl}_{2}$, and $10 \mathrm{mM} \mathrm{HEPES}$, pH 7.6), continuously perfused at $0.3 \mathrm{~mL} / \mathrm{min}$, and maintained at $14-17^{\circ} \mathrm{C}$. Physiological experiments on neuronal excitability were performed in highly divalent (HiDi) saline (368 mM NaCl, $8 \mathrm{mM} \mathrm{KCl}$, 13.8 $\mathrm{mM} \mathrm{CaCl}_{2}, 115 \mathrm{mM} \mathrm{MgCl}_{2}$, and $10 \mathrm{mM}$ HEPES, $\mathrm{pH}$ 7.6), which increases the spiking 
threshold of neurons and therefore curtails polysynaptic influences. Intracellular recordings were obtained using 5-10 M $\Omega$ sharp microelectrodes filled with an electrolyte $\left(0.6 \mathrm{M} \mathrm{K}_{2} \mathrm{SO}_{4}\right.$ plus $60 \mathrm{mM}$ $\mathrm{KCl}$ ). Grass S88 stimulator was used to provide timing signals for intracellular stimulation. Positive current pulses lasting 3 seconds were used to test excitability of single neurons, with the stimulus interval being 30 seconds. Electrophysiological recordings were digitized online using AxoScope (Molecular Devices, Sunnyvale, CA) and plotted by CorelDraw (Corel Corporation, Ottawa, ON, Canada). Bar graphs were plotted with Prism (version 8, GraphPad Software, La Jolla, CA). Data are expressed as the mean \pm S.E.M. All statistical tests were performed using Prism. When the data showed significant effects in ANOVA, individual comparisons were performed with Bonferroni's correction.

\section{Microinjection of plasmids}

For neurons in the Aplysia buccal ganglion that didn't respond to apATRP, we established two groups. The control neurons were microinjected with the DNA construct pNEX3-EGFP, and the experimental neurons were microinjected with a mixture of pNEX3-EGFP and pNEX3-apATRPR. The EGFP was used as a marker of gene expression. We microinjected the plasmids by pressure injection. The pressure ranged from 20 to 30 psi. To observe the microinjected plasmid volume, we mixed the plasmids with $2 \%$ fast green buffer (20 mM HEPES, $200 \mathrm{mM} \mathrm{KCl}, \mathrm{pH}=7.37$ ) at 1:1. We stopped injecting when the plasmid volume expanded $1 / 3$ of the volume of the injected neuron and the neuron could be seen to turn green due to fast green (see Fig 1B). In the experimental group, if neurons had green fluorescence under an Olympus fluorescence microscope (see Fig 1C), we assumed that these neurons expressed both EGFP and apATRPR.

\section{Culture of Aplysia neurons and detection of plasmid expression}


After injection, the buccal ganglia were cultured at $18^{\circ} \mathrm{C}$. The culture medium was made up of an aliquot of Aplysia hemolymph and L15 at 1:1 by volume [79, 80]. Then, we added a $1 \%$ total volume of $50 \mathrm{mg} / \mathrm{ml}$ ampicillin sodium salt (Sigma-Aldrich: A9518-25G-9) solution and a 1\% total volume of 200 mM L-glutamine (Sigma-Aldrich: V900419-100G). The culture medium was prepared freshly each time. Aplysia hemolymph was prepared from large live Aplysia (> $350 \mathrm{gm})$ using a syringe through a $0.22 \mu \mathrm{m}$ filter, and aliquots of hemolymph were stored at $-80{ }^{\circ} \mathrm{C}$. $\mathrm{L}-15$ medium powder (Leibovitz) (Gibco: 41300039) was supplemented with the salts to make 1-liter solution (L15 power 13.7 g, NaCl 15.4 g, D-Glucose 6.24 g, $\mathrm{MgSO}_{4} 3.15 \mathrm{~g}, \mathrm{KCl} 0.35 \mathrm{~g}, \mathrm{NaHCO}_{3} 0.17 \mathrm{~g}$, $\mathrm{MgCl}_{2} \cdot 6 \mathrm{H}_{2} \mathrm{O} 5.49 \mathrm{~g}, \mathrm{CaCl}_{2} 1.08 \mathrm{~g}$, HEPES $3.53 \mathrm{~g}, \mathrm{pH}, 7.4-7.5$; osmolarity: $1000 \mathrm{mmol} / \mathrm{kg}$ ). Then, $10 \mathrm{ml}$ of $100 \times(5 \mathrm{mg} / \mathrm{ml})$ gentamicin sulfate salt (Sigma-Aldrich: E003632-1G) solution was added. The mixture was filter-sterilized through a $0.22 \mu \mathrm{m}$ filter, and stored at $4^{\circ} \mathrm{C}$.

During ganglia culture, the gene expression was observed using an Olympus fluorescence microscope every day. If the neurons in the control and experimental groups expressed green fluorescence, we then evaluated the activity of apATRP in these neurons using the procedures described in the "Electrophysiology" section.

\section{Results}

\section{Construction of plasmid pNEX3-ATRPR}

The recombinant plasmid, pNEX3-apATRPR, was identified by digestion and the DNA sequencing (Fig 1A). The verified recombinant plasmid was used to microinject Aplysia neurons in the experimental group. The plasmid pNEX3-EGFP was microinjected into neurons in the control group. 
$<$ Fig 1. Verification of pNEX3-apATRPR and apATRPR genes, and B1/B2 neurons expressing the receptor apATRPR. (A) Gel electrophoresis of the plasmid pNEX3-apATRPR (approximately $4274 \mathrm{bp}$ ) and apATRPR gene (approximately $1215 \mathrm{bp}$ ) digested from the BamHI-KpnI restriction fragment of pNEX3 (approximately 3059 bp). apATRPR gene has been verified by sequencing. Lane 1: plasmid pNEX3-apATRPR; lane 2: apATRPR gene (the lower band) and pNEX3 vector (the upper band); M: marker. (B) The caudal surface of a buccal ganglion viewed with a regular light source. B1/B2 and other neurons on the left side were microinjected with plasmids pNEX3apATRPR and pNEX3-EGFP, and B1/B2 and other neurons on the right side were microinjected with only plasmid pNEX3-EGFP. Arrows and arrowheads: cells with successful injection (fast green). (C) B1/B2 neurons on both sides showed bright fluorescent green (arrows) under a fluorescence microscope. The left B1/B2 neuron expressed apATRPR and EGFP, and the right B1/B2 neuron expressed EGFP. Other neurons marked with arrowheads in (B) did not express injected genes. (D-E) A magnified view of the injected neurons in (C) showing left B1/B2 neuron (D) and right B1/B2 neuron (E). Scale bars in B and C: $500 \mu \mathrm{m}$ (scale bar in C is for B and C); Scale bars in D and E: $200 \mu \mathrm{m}$ (scale bar in E is for D and E). EN: esophageal nerve; BN1: buccal nerve 1; BN3: buccal nerve 3; RN: radular nerve.>

\section{apATRP has no effect on neurons B1/B2}

To demonstrate that apATRPR might function as an endogenous receptor of apATRP, we sought to find a target neuron that did not natively express apATRPR in the buccal ganglia. We selected a larger neuron, B8 $(\sim 150 \mu \mathrm{m})$, and examined B8 excitability changes in response to apATRP. apATRP could increase B8 excitability (Fig $2 \mathrm{~A}-\mathrm{B}, \mathrm{F}(3,6)=14.89, \mathrm{p}<0.01, \mathrm{n}=3$ ), suggesting that B8 might contain a receptor(s) for apATRP. Therefore, B8 neurons were excluded. After testing 
other neurons, we found that another large neuron B1/B2 $(\sim 210 \mu \mathrm{m})$ didn't respond to apATRP (Fig $2 \mathrm{C}-\mathrm{D}, \mathrm{F}(3,9)=1.00, \mathrm{p}>0.05, \mathrm{n}=4)$, and it was used as the target neuron.

$<$ Fig 2. apATRP enhanced B8 excitability but not B1/B2 excitability. (A-B) apATRP increased B8 excitability at $10^{-5} \mathrm{M}$ but not at $10^{-6} \mathrm{M}$. (A) A representative example. (B) Group data. Bonferroni post hoc tests: $*(p<0.05), * *(p<0.01)$. Error bars, SE. (C-D) apATRP had no significant effect on B1/B2 excitability. (C) A representative example. (D) Group data. Bars in A and C denote current injections. Recordings in $(\mathrm{A}, \mathrm{C})$ were made in high divalent saline.>

\section{Microinjection of pNEX3-apATRPR into the target neuron}

In each hemi-ganglion of the buccal ganglion, there are one B1 and one B2 neuron. Thus, there are four B1/B2 neurons on both sides of the buccal ganglion. We set up two groups: the plasmid pNEX3-EGFP mixture with fast green microinjected into B1/B2 neurons as the control group, and the plasmid pNEX3-EGFP and pNEX3-apATRPR mixture with fast green microinjected into the contralateral B1/B2 neurons as the experimental group. Fast green can be visualized with a regular light source in a microscope, which allowed us to make sure that the plasmid injection was successful (Fig 1B).

After injection, we placed the buccal ganglion into the cell culture for 1-3 days, and observed whether B1/B2 neurons exhibited green fluorescence. If we observed green fluorescence, we considered that neurons were successful in expressing the EGFP in the control group, and coexpressing the apATRPR and EGFP in the experimental group. In 32 cells injected with these plasmids, $30 \%$ of the cells subsequently expressed the genes.

apATRP could enhance the excitability of B1/B2 neurons that exogenously expressed apATRPR 
We perfused apATRP into the recording dish and tested B1/B2 excitability. The results showed that B1/B2 excitability in the experimental group was enhanced (Fig $3 \mathrm{~A}-\mathrm{B}, \mathrm{F}(3,9)=44.84, \mathrm{p}<$ 0.0001, $\mathrm{n}=4$ ), and B1/B2 excitability in the control group showed no significant changes (Fig 3 C$\mathrm{D}, \mathrm{F}(3,6)=1.60, \mathrm{p}>0.05, \mathrm{n}=3)$. The data indicated that the neuropeptide receptor, apATRPR, could mediate the excitability increase in native Aplysia neurons in response to its ligand, apATRP.

\section{$<$ Fig 3. apATRP increased the excitability of B1/B2 neurons that expressed the receptor}

apATRPR. (A-B) At $10^{-6} \mathrm{M}$ and $10^{-5} \mathrm{M}$, apATRP increased B1/B2 excitability, which expressed the receptor apATRPR. (A) Representative example. (B) Group data. Bonferroni post hoc tests: *** (p< 0.001). Error bars, SE. (C-D) apATRP had no significant effects on B1/B2 neurons that do not express the receptor apATRPR. (C) A representative example. (D) Group data. Recordings in (A, C) were made in high divalent saline. Bars in A and C denote current injections in B1/B2.>

\section{Discussion}

In this work, we have characterized physiological functions of a neuropeptide receptor, apATRPR, expressed in Aplysia neurons. Earlier [39, 50], we showed that apATRPR is expressed in the Aplysia CNS. Moreover, apATRP and several other ligands can activate apATRPR expressed in a cell line, and these effects matched their enhancing effects on B61/B62excitability. These pieces of evidence are consistent with the notion that apATRPR may mediate the effects of ATRP on B61/B62 neurons. However, prior to the present work, no direct evidence showed that apATRPR could mediate excitability increase in an Aplysia neuron. This evidence is critical given two considerations. First, apATRPR activity in a cell line is often measured by a ligand's ability to increase IP1 concentration 
in Gaq signaling pathway, whereas excitability increase likely requires an ultimate action of a GPCR on some specific ionic channels [81]. Second, there might be additional ATRP receptor(s) other than the identified apATRPR in Aplysia that might mediate excitability increase. Indeed, two allatotropin receptors have been characterized in annelid Platynereis [48], which together with mollusc Aplysia, belongs to a superphylum: lophotrochozoa.

To provide further evidence, we sought to determine if apATRPR might mediate excitability increase in a neuron that does not express apATRPR. Among several buccal neurons, B1/B2 neurons did not show an excitability increase in response to apATRP. To express exogenous genes in Aplysia neurons, we used the plasmid vector pNEX3 $[5,67-69,75,76]$ to construct pNEX3-EGFP and pNEX3-apATRPR, and microinjected B1/B2 neurons in the control group with pNEX3-EGFP, those in the experimental group with both pNEX3-EGFP and pNEX3-apATRPR. B1/B2 neurons in the experimental group could be excited by apATRP, whereas B1/B2 neurons in the control group could not. Thus, our study provides the first evidence that apATRPR indeed mediates excitability increase in a neuron that does not express apATRPR. Taken together with earlier work showing that pNEX $\delta$ or pNEX3 can express GPCRs for glutamate or octopamine [64, 69], pNEX, including pNEX $\delta$ and pNEX3, proves to be an effective plasmid to express GPCRs for both small molecule transmitters and neuropeptides in Aplysia neurons.

We expect that such a procedure could be readily applied to demonstrate physiological functions of neuropeptide receptors in native neurons in model systems with reasonably large identifiable neurons, such as other molluscs, annelids and possibly some arthropods. Notably, compared with invertebrate genetic organisms C elegans [82] and Drosophila [83], life spans of molluscs and annelids are relatively long, making it difficult to use transgenes to manipulate gene expression. 
Consequently, the procedure described in this paper should be particularly useful in these animals to study functions of genes in native neurons.

In summary, we provide direct evidence indicating that the neuropeptide receptor, apATRPR, is sufficient to mediate an excitability increase to its ligand, apATRP, in Aplysia neurons. This is a further proof that Aplysia is an advantageous model system for the study of peptidergic neuromodulation in well-defined neural circuits for feeding, locomotion and other behaviors.

\section{Acknowledgements}

Not applicable.

\section{Authors' contributions}

Conceptualization: Guo Zhang, Bong-Kiun Kaang, Jian Jing

Data curation: Guo Zhang, Shi-Qi Guo, Si-Yuan Yin, Wang-Ding Yuan, Ping Chen, Ji-Il Kim, HuiYing Wang

Formal analysis: Wang-Ding Yuan, Ji-Il Kim, Hui-Ying Wang

Funding acquisition: Guo Zhang, Hai-Bo Zhou, Abraham J. Susswein, Bong-Kiun Kaang, Jian Jing Methodology: Shi-Qi Guo, Wang-Ding Yuan, Ping Chen

Project administration: Hai-Bo Zhou, Abraham J. Susswein, Bong-Kiun Kaang, Jian Jing

Supervision: Abraham J. Susswein, Bong-Kiun Kaang, Jian Jing

Validation: Guo Zhang, Shi-Qi Guo, Wang-Ding Yuan, Jian Jing

Writing-original draft: Guo Zhang, Abraham J. Susswein, Bong-Kiun Kaang, Jian Jing 


\section{Reference}

1. Abid MSR, Mousavi S, Checco JW. Identifying Receptors for Neuropeptides and Peptide

Hormones: Challenges and Recent Progress. ACS Chem Biol. 2021;16(2):251-63. Epub 2021/02/05. doi: 10.1021/acschembio.0c00950. PubMed PMID: 33539706.

2. Zhang G, Guo SQ, Wang HY, Li YD, Jiang HM, Yu K, et al. Functional studies on neuropeptides and receptors in model animal Aplysia (in Chinese). Sci Sin Vitae. 2021;51. doi: 10.1360/SSV-20210155.

3. Kaang BK, Pfaffinger PJ, Grant SG, Kandel ER, Furukawa Y. Overexpression of an Aplysia shaker K+ channel gene modifies the electrical properties and synaptic efficacy of identified Aplysia neurons. Proc Natl Acad Sci U S A. 1992;89(3):1133-7. Epub 1992/02/01. doi: 10.1073/pnas.89.3.1133. PubMed PMID: 1310540; PubMed Central PMCID: PMCPMC48400.

4. Kaang BK, Kandel ER, Grant SGN. Activation of cAMP-responsive genes by stimuli that produce long- term facilitation in Aplysia sensory neurons. Neuron. 1993;10:427-35.

5. Kaang BK. Parameters influencing ectopic gene expression in Aplysia neurons. Neurosci Lett. 1996;221(1):29-32. Epub 1996/12/27. doi: 10.1016/s0304-3940(96)13279-1. PubMed PMID: 9014173.

6. Hurwitz I, Susswein AJ. B64, a newly identified central pattern generator element producing a phase switch from protraction to retraction in buccal motor programs of Aplysia californica. J Neurophysiol. 1996;75(4):1327-44.

7. Jing J, Weiss KR. Neural mechanisms of motor program switching in Aplysia. J Neurosci. 2001;21:7349-62.

8. Kandel ER. The molecular biology of memory storage: a dialogue between genes and synapses. 
Science. 2001;294(5544):1030-8. PubMed PMID: 11691980.

9. Brembs B, Lorenzetti FD, Reyes FD, Baxter DA, Byrne JH. Operant reward learning in Aplysia: neuronal correlates and mechanisms. Science. 2002;296(5573):1706-9. PubMed PMID: 12040200.

10. Jing J, Weiss KR. Interneuronal basis of the generation of related but distinct motor programs in Aplysia: implications for current neuronal models of vertebrate intralimb coordination. J Neurosci. 2002;22:6228-38.

11. Dembrow NC, Jing J, Proekt A, Romero A, Vilim FS, Cropper EC, et al. A newly identified buccal interneuron initiates and modulates feeding motor programs in Aplysia. J Neurophysiol. 2003;90(4):2190-204. PubMed PMID: 12801904.

12. Hurwitz I, Kupfermann I, Weiss KR. Fast synaptic connections from CBIs to pattern-generating neurons in Aplysia: initiation and modification of motor programs. J Neurophysiol. 2003;89(4):212036. PubMed PMID: 12686581.

13. Jing J, Vilim FS, Wu JS, Park JH, Weiss KR. Concerted GABAergic actions of Aplysia feeding interneurons in motor program specification. J Neurosci. 2003;23(12):5283-94. PubMed PMID: 12832553.

14. Dembrow NC, Jing J, Brezina V, Weiss KR. A specific synaptic pathway activates a conditional plateau potential underlying protraction phase in the Aplysia feeding central pattern generator. J Neurosci. 2004;24(22):5230-8. PubMed PMID: 15175393.

15. Jing J, Weiss KR. Generation of variants of a motor act in a modular and hierarchical motor network. Curr Biol. 2005;15:1712-21.

16. Jing J, Vilim FS, Cropper EC, Weiss KR. Neural analog of arousal: persistent conditional activation of a feeding modulator by serotonergic initiators of locomotion. $\mathrm{J}$ Neurosci. 
2008;28(47):12349-61. PubMed PMID: 19020028.

17. Mozzachiodi R, Lorenzetti FD, Baxter DA, Byrne JH. Changes in neuronal excitability serve as a mechanism of long-term memory for operant conditioning. Nat Neurosci. 2008;11(10):1146-8. Epub 2008/09/09. doi: nn.2184 [pii]10.1038/nn.2184. PubMed PMID: 18776897.

18. Sasaki K, Jing J, Due MR, Weiss KR. An input-representing interneuron regulates spike timing and thereby phase switching in a motor network. J Neurosci. 2008;28(8):1916-28. PubMed PMID: 18287508.

19. Jing J, Gillette R, Weiss KR. Evolving concepts of arousal: insights from simple model systems. Rev Neurosci. 2009;20:405-27.

20. Sasaki K, Brezina V, Weiss KR, Jing J. Distinct inhibitory neurons exert temporally specific control over activity of a motoneuron receiving concurrent excitation and inhibition. $\mathrm{J}$ Neurosci. 2009;29:11732-44.

21. Jing J, Sasaki K, Perkins MH, Siniscalchi MJ, Ludwar BC, Cropper EC, et al. Coordination of distinct motor structures through remote axonal coupling of projection interneurons. J Neurosci. 2011;31(43):15438-49. PubMed PMID: 22031890.

22. Wan Q, Jiang XY, Negroiu AM, Lu SG, McKay KS, Abrams TW. Protein kinase C acts as a molecular detector of firing patterns to mediate sensory gating in Aplysia. Nat Neurosci. 2012;15(8):1144-52. Epub 2012/07/10. doi: 10.1038/nn.3158 nn.3158 [pii]. PubMed PMID: 22772333.

23. Sasaki K, Cropper EC, Weiss KR, Jing J. Functional differentiation of a population of electrically coupled heterogeneous elements in a microcircuit. J Neurosci. 2013;33(1):93-105. Epub 2013/01/04. doi: 10.1523/JNEUROSCI.3841-12.2013. PubMed PMID: 23283325. 
24. Wu JS, Wang N, Siniscalchi MJ, Perkins MH, Zheng YT, Yu W, et al. Complementary interactions between command-like interneurons that function to activate and specify motor programs.

J Neurosci. 2014;34(19):6510-21. doi: Doi 10.1523/Jneurosci.5094-13.2014. PubMed PMID: WOS:000336380500010.

25. Jing J, Alexeeva V, Chen SA, Yu K, Due MR, Tan LN, et al. Functional characterization of a vesicular glutamate transporter in an interneuron that makes excitatory and inhibitory synaptic connections in a molluscan neural circuit. J Neurosci. 2015;35(24):9137-49. doi: 10.1523/JNEUROSCI.0180-15.2015. PubMed PMID: 26085636; PubMed Central PMCID: PMC4469739.

26. Tam S, Hurwit I, Chiel HJ, Susswein AJ. Multiple local synaptic modifications at specific sensorimotor connections after learning are associated with behavioral adaptations that are components of a global response change. J Neurosci. 2020;40(22):4363-71. PubMed PMID: WOS:000535695400008.

27. Zhang G, Yu K, Wang T, Chen TT, Yuan WD, Yang F, et al. Synaptic mechanisms for motor variability in a feedforward network. Sci Adv. 2020;6(25):eaba4856. Epub 2020/09/17. doi: 10.1126/sciadv.aba4856. PubMed PMID: 32937495.

28. Evans CG, Barry MA, Jing J, Perkins MH, Weiss KR, Cropper EC. The complement of projection neurons activated determines the type of feeding motor program in Aplysia. Front Neural Circuits. 2021;15:685222. Epub 2021/06/29. doi: 10.3389/fncir.2021.685222. PubMed PMID: 34177471; PubMed Central PMCID: PMCPMC8222659.

29. Hening WA, Walters ET, Carew TJ, Kandel ER. Motorneuronal control of locomotion in Aplysia. Brain Res. 1979;179(2):231-53. 
30. Fredman SM, Jahan-Parwar B. Command neurons for locomotion in Aplysia. J Neurophysiol. $1983 ; 49: 1092-117$.

31. Cropper EC, Evans CG, Hurwitz I, Jing J, Proekt A, Romero A, et al. Feeding neural networks in the mollusc Aplysia. Neurosignals. 2004;13(1-2):70-86. PubMed PMID: 15004426.

32. Bruno AM, Frost WN, Humphries MD. Modular deconstruction reveals the dynamical and physical building blocks of a locomotion motor program. Neuron. 2015;86(1):304-18. doi: 10.1016/j.neuron.2015.03.005. PubMed PMID: 25819612.

33. Yang CY, Yu K, Wang Y, Chen SA, Liu DD, Wang ZY, et al. Aplysia locomotion: Network and behavioral actions of GdFFD, a D-amino acid-containing neuropeptide. PLoS One. 2016;11(1):e0147335. Epub 2016/01/23. doi: 10.1371/journal.pone.0147335. PubMed PMID: 26796097; PubMed Central PMCID: PMC4721866.

34. Zhang G, Vilim FS, Liu DD, Romanova EV, Yu K, Yuan WD, et al. Discovery of leucokinin-like neuropeptides that modulate a specific parameter of feeding motor programs in the molluscan model, Aplysia. The Journal of biological chemistry. 2017;292:18775-89. Epub 2017/09/20. doi: 10.1074/jbc.M1 17.795450. PubMed PMID: 28924050; PubMed Central PMCID: PMCPMC5704463. 35. Zhang G, Yuan WD, Vilim FS, Romanova EV, Yu K, Yin SY, et al. Newly identified Aplysia SPTR-Gene Family-Derived peptides: localization and function. ACS Chem Neurosci. 2018;9:204153. doi: 10.1021/acschemneuro.7b00513. PubMed PMID: 29543430.

36. Jiang HM, Yang Z, Xue YY, Wang HY, Guo SQ, Xu JP, et al. Identification of an allatostatin C signaling system in mollusc Aplysia. Sci Rep. 2022;12(1):1213. Epub 2022/01/26. doi: 10.1038/s41598-022-05071-8. PubMed PMID: 35075137; PubMed Central PMCID: PMCPMC8786951. 
37. Furukawa Y, Nakamaru K, Wakayama H, Fujisawa Y, Minakata H, Ohta S, et al. The enterins: a novel family of neuropeptides isolated from the enteric nervous system and CNS of Aplysia. J Neurosci. 2001;21(20):8247-61. PubMed PMID: 11588196.

38. Furukawa Y, Nakamaru K, Sasaki K, Fujisawa Y, Minakata H, Ohta S, et al. PRQFVamide, a novel pentapeptide identified from the CNS and gut of Aplysia. J Neurophysiol. 2003;89(6):3114-27. PubMed PMID: 12612009.

39. Jing J, Sweedler JV, Cropper EC, Alexeeva V, Park JH, Romanova EV, et al. Feedforward compensation mediated by the central and peripheral actions of a single neuropeptide discovered using representational difference analysis. J Neurosci. 2010;30(49):16545-58. PubMed PMID: 21147994.

40. Vilim FS, Sasaki K, Rybak IA, Alexeeva V, Cropper EC, Jing J, et al. Distinct mechanisms produce functionally complementary actions of neuropeptides that are structurally related but derived from different precursors. J Neurosci. 2010;30:131-47.

41. Wu JS, Vilim FS, Hatcher NG, Due MR, Sweedler JV, Weiss KR, et al. Composite modulatory feedforward loop contributes to the establishment of a network state. J Neurophysiol. 2010;103:217484. PubMed PMID: 20181731.

42. Romanova EV, Sasaki K, Alexeeva V, Vilim FS, Jing J, Richmond TA, et al. Urotensin II in invertebrates: from structure to function in Aplysia californica. PLoS One. 2012;7(11):e48764. Epub 2012/11/13. doi: 10.1371/journal.pone.0048764. PubMed PMID: 23144960; PubMed Central PMCID: PMCPMC3493602.

43. Bai L, Livnat I, Romanova EV, Alexeeva V, Yau PM, Vilim FS, et al. Characterization of GdFFD, a D-amino acid-containing neuropeptide that functions as an extrinsic modulator of the Aplysia feeding circuit. J Biol Chem. 2013;288(46):32837-51. doi: DOI 10.1074/jbc.M113.486670. PubMed PMID: 
WOS:000328841700003.

44. Cropper EC, Friedman AK, Jing J, Perkins MH, Weiss KR. Neuromodulation as a mechanism for the induction of repetition priming. Curr Opin Neurobiol. 2014;29:33-8. doi: 10.1016/j.conb.2014.04.011. PubMed PMID: 25261622; PubMed Central PMCID: PMCPMC4233203.

45. Livnat I, Tai HC, Jansson ET, Bai L, Romanova EV, Chen TT, et al. A D-amino acid-containing neuropeptide discovery funnel. Anal Chem. 2016;88(23):11868-76. Epub 2016/10/28. doi: 10.1021/acs.analchem.6b03658. PubMed PMID: 27788334; PubMed Central PMCID: PMC5144109. 46. Cropper EC, Jing J, Vilim FS, Barry MA, Weiss KR. Multifaceted expression of peptidergic modulation in the feeding system of Aplysia. ACS Chem Neurosci. 2018:1917-27. doi: 10.1021/acschemneuro.7b00447. PubMed PMID: 29309115.

47. Cropper EC, Jing J, Vilim FS, Weiss KR. Peptide cotransmitters as dynamic, intrinsic modulators of network activity. Front Neural Circuits. 2018;12:78. Epub 2018/10/20. doi: 10.3389/fncir.2018.00078. PubMed PMID: 30333732; PubMed Central PMCID: PMCPMC6176060. 48. Bauknecht P, Jekely G. Large-scale combinatorial deorphanization of Platynereis neuropeptide GPCRs. Cell Rep. 2015;12(4):684-93. doi: 10.1016/j.celrep.2015.06.052. PubMed PMID: 26190115. 49. Checco JW, Zhang G, Yuan WD, Yu K, Yin SY, Roberts-Galbraith RH, et al. Molecular and physiological characterization of a receptor for d-amino acid-containing neuropeptides. ACS Chem Biol. 2018;13(5):1343-52. doi: 10.1021/acschembio.8b00167. PubMed PMID: 29543428; PubMed Central PMCID: PMCPMC5962930.

50. Checco JW, Zhang G, Yuan WD, Le ZW, Jing J, Sweedler JV. Aplysia allatotropin-related peptide and its newly identified d-amino acid-containing epimer both activate a receptor and a neuronal target. 
The Journal of biological chemistry. 2018;293(43):16862-73. doi: 10.1074/jbc.RA118.004367. PubMed PMID: 30194283; PubMed Central PMCID: PMCPMC6204918.

51. Dubos MP, Zels S, Schwartz J, Pasquier J, Schoofs L, Favrel P. Characterization of a tachykinin signalling system in the bivalve mollusc Crassostrea gigas. Gen Comp Endocrinol. 2018;266:110-8. Epub 2018/05/11. doi: 10.1016/j.ygcen.2018.05.003. PubMed PMID: 29746853.

52. Veenstra JA. Neurohormones and neuropeptides encoded by the genome of Lottia gigantea, with reference to other mollusks and insects. Gen Comp Endocr. 2010;167(1):86-103. doi: 10.1016/j.ygcen.2010.02.010. PubMed PMID: WOS:000277643800012.

53. Kataoka H, Toschi A, Li JP, Carney RL, Schooley DA, Kramer SJ. Identification of an allatotropin from adult manduca sexta. Science. 1989;243(4897):1481-3. Epub 1989/03/17. doi: 10.1126/science.243.4897.1481. PubMed PMID: 17839751.

54. Elekonich MM, Horodyski FM. Insect allatotropins belong to a family of structurally-related myoactive peptides present in several invertebrate phyla. Peptides. 2003;24(10):1623-32. PubMed PMID: 14706542.

55. Yamanaka N, Yamamoto S, Zitnan D, Watanabe K, Kawada T, Satake H, et al. Neuropeptide receptor transcriptome reveals unidentified neuroendocrine pathways. PLoS One. 2008;3(8):e3048. Epub 2008/08/30. doi: 10.1371/journal.pone.0003048. PubMed PMID: 18725956; PubMed Central PMCID: PMCPMC2516173.

56. Nouzova M, Brockhoff A, Mayoral JG, Goodwin M, Meyerhof W, Noriega FG. Functional characterization of an allatotropin receptor expressed in the corpora allata of mosquitoes. Peptides. 2012;34(1):201-8. Epub 2011/08/16. doi: 10.1016/j.peptides.2011.07.025. PubMed PMID: 21839791; PubMed Central PMCID: PMCPMC3233642. 
57. Vuerinckx K, Verlinden H, Lindemans M, Broeck JV, Huybrechts R. Characterization of an allatotropin-like peptide receptor in the red flour beetle, Tribolium castaneum. Insect Biochem Mol Biol. 2011;41(10):815-22. Epub 2011/07/12. doi: 10.1016/j.ibmb.2011.06.003. PubMed PMID: 21742031.

58. Sakurai T, Amemiya A, Ishii M, Matsuzaki I, Chemelli RM, Tanaka H, et al. Orexins and orexin receptors: A family of hypothalamic neuropeptides and $G$ protein-coupled receptors that regulate feeding behavior. Cell. 1998;92(5):573-85. PubMed PMID: WOS:000072406000015.

59. Jekely G. Global view of the evolution and diversity of metazoan neuropeptide signaling. Proc Natl Acad Sci U S A. 2013;110(21):8702-7. doi: 10.1073/pnas.1221833110. PubMed PMID: 23637342 ; PubMed Central PMCID: PMCPMC3666674.

60. Mirabeau O, Joly JS. Molecular evolution of peptidergic signaling systems in bilaterians. Proc Natl Acad Sci U S A. 2013;110(22):E2028-37. doi: 10.1073/pnas.1219956110. PubMed PMID: 23671109; PubMed Central PMCID: PMCPMC3670399.

61. Kaang BK, Pfaffinger PJ, Grant SGN, Kandel ER, Furukawa Y. Overexpression of an Aplysia shaker $\mathrm{K}^{+}$channel gene modifies the electrical properties and synaptic efficacy of identified Aplysia neurons. Proc Natl Acad Sci USA. 1992;89:1133-7.

62. Han JH, Yim SW, Lim CS, Park CW, Kaang BK. Expression of a non-inactivating K+ channel driven by a rat heat shock promoter increased the resting potential in Aplysia silent neurons. Neurosci Res. 1999;34(1):13-9. Epub 1999/07/21. doi: 10.1016/s0168-0102(99)00027-9. PubMed PMID: 10413322.

63. Lee JA, Kim HK, Kim KH, Han JH, Lee YS, Lim CS, et al. Overexpression of and RNA interference with the CCAAT enhancer-binding protein on long-term facilitation of Aplysia sensory to 
motor synapses. Learn Mem. 2001;8(4):220-6. Epub 2001/09/05. doi: 10.1101/1m.40201. PubMed PMID: 11533225; PubMed Central PMCID: PMCPMC311377.

64. Chang DJ, Lim CS, Lee JA, Kaang BK. Synaptic facilitation by ectopic octopamine and 5-HT receptors in Aplysia. Brain Res Bull. 2003;60(1-2):73-9. Epub 2003/05/03. doi: 10.1016/s03619230(03)00016-9. PubMed PMID: 12725895.

65. Choi JH, Lee JA, Yim SW, Lim CS, Lee CH, Lee YD, et al. Using an Aplysia two-hybrid system to examine the interactions between transcription factors involved in long-term facilitation in the nervous system of Aplysia. Learn Memory. 2003;10(1):40-3. doi: 10.1101/1m.55303. PubMed PMID: WOS:000180784000005.

66. Han JH, Lim CS, Lee YS, Kandel ER, Kaang BK. Role of Aplysia cell adhesion molecules during 5-HT-induced long-term functional and structural changes. Learn Mem. 2004;11(4):421-35. Epub 2004/07/16. doi: 10.1101/lm.61104. PubMed PMID: 15254221; PubMed Central PMCID: PMCPMC498325.

67. Pollak DD, Minh BQ, Cicvaric A, Monje FJ. A novel fibroblast growth factor receptor family member promotes neuronal outgrowth and synaptic plasticity in Aplysia. Amino Acids. 2014;46(11):2477-88. Epub 2014/07/26. doi: 10.1007/s00726-014-1803-2. PubMed PMID: 25059541; PubMed Central PMCID: PMCPMC4200351.

68. Ferguson L, Hu J, Cai D, Chen S, Dunn TW, Pearce K, et al. Isoform specificity of PKMs during long-term facilitation in Aplysia is mediated through stabilization by KIBRA. J Neurosci. 2019;39(44):8632-44. Epub 2019/09/21. doi: 10.1523/JNEUROSCI.0943-19.2019. PubMed PMID: 31537706; PubMed Central PMCID: PMCPMC6820206.

69. Whim MD, Kaczmarek LK. Expression of a foreign G-protein coupled receptor modulates the 
excitability of the peptidergic bag cell neurons of Aplysia. Neurosci Lett. 1998;258(3):143-6. PubMed PMID: 9885951.

70. Kim HK, Kaang BK. Truncated green fluorescent protein mutants and their expression in Aplysia neurons. Brain Res Bull. 1998;47(1):35-41. Epub 1998/10/10. doi: 10.1016/s0361-9230(98)00020-3. PubMed PMID: 9766387.

71. Chang DJ, Li XC, Lee YS, Kim HK, Kim US, Cho NJ, et al. Activation of a heterologously expressed octopamine receptor coupled only to adenylyl cyclase produces all the features of presynaptic facilitation in Aplysia sensory neurons. Proc Natl Acad Sci U S A. 2000;97(4):1829-34. PubMed PMID: 10677541.

72. Lee YS, Lee JA, Jung J, Oh U, Kaang BK. The cAMP-dependent kinase pathway does not sensitize the cloned vanilloid receptor type 1 expressed in xenopus oocytes or Aplysia neurons. Neurosci Lett. 2000;288(1):57-60. Epub 2000/06/28. doi: 10.1016/s0304-3940(00)01208-8. PubMed PMID: 10869815.

73. Lee JA, Lim CS, Lee SH, Kim H, Nukina N, Kaang BK. Aggregate formation and the impairment of long-term synaptic facilitation by ectopic expression of mutant huntingtin in Aplysia neurons. $\mathrm{J}$ Neurochem. 2003;85(1):160-9. Epub 2003/03/19. doi: 10.1046/j.1471-4159.2003.01650.x. PubMed PMID: 12641738.

74. Jin I, Kassabov S, Kandel ER, Hawkins RD. Possible novel features of synaptic regulation during long-term facilitation in Aplysia. Learn Mem. 2021;28(7):218-27. Epub 2021/06/17. doi: 10.1101/lm.053124.120. PubMed PMID: 34131053; PubMed Central PMCID: PMCPMC8212780.

75. Sahly I, Erez H, Khoutorsky A, Shapira E, Spira ME. Effective expression of the green fluorescent fusion proteins in cultured Aplysia neurons. J Neurosci Methods. 2003;126(2):111-7. Epub 2003/06/20. 
doi: 10.1016/s0165-0270(03)00072-4. PubMed PMID: 12814835.

76. Dunn TW, Sossin WS. Excitatory postsynaptic calcium transients at Aplysia sensory-motor neuron synapses allow for quantal examination of synaptic strength over multiple days in culture. Learn Mem. 2021;28(9):277-90. Epub 2021/08/18. doi: 10.1101/1m.052639.120. PubMed PMID: 34400529; PubMed Central PMCID: PMCPMC8372562.

77. Nagahama T, Suzuki T, Yoshikawa S, Iseki M. Functional transplant of photoactivated adenylyl cyclase (PAC) into Aplysia sensory neurons. Neurosci Res. 2007;59(1):81-8. doi: 10.1016/j.neures.2007.05.015. PubMed PMID: WOS:000250126100012.

78. Dyer J, Sossin WS. Characterization of the role of eIF4G in stimulating cap- and IRES-dependent translation in Aplysia neurons. PLoS One. 2013;8(9):e74085. Epub 2013/09/11. doi: 10.1371/journal.pone.0074085. PubMed PMID: 24019950; PubMed Central PMCID: PMCPMC3760813.

79. Fejtl M, Gyori J, Carpenter DO. Mercuric(II) chloride modulates single-channel properties of carbachol-activated Cl- channels in cultured neurons of Aplysia californica. Cell Mol Neurobiol. 1994;14(6):665-74. Epub 1994/12/01. doi: 10.1007/BF02088675. PubMed PMID: 7641227.

80. Fejtl M, Carpenter DO. Neurite outgrowth is enhanced by conditioning factor(s) released from central ganglia of Aplysia-californica. Neuroscience Letters. 1995;199(1):33-6. doi: Doi 10.1016/0304-3940(95)12004-N. PubMed PMID: WOS:A1995TC53400009.

81. Padgett CL, Slesinger PA. GABAB receptor coupling to G-proteins and ion channels. Adv Pharmacol. 2010;58:123-47. Epub 2010/07/27. doi: 10.1016/S1054-3589(10)58006-2. PubMed PMID: 20655481.

82. Sugi T. Genome Editing of C. elegans. Methods Mol Biol. 2017;1630:247-54. Epub 2017/06/24. 
bioRxiv preprint doi: https://doi.org/10.1101/2022.02.14.480444; this version posted February 14 , 2022. The copyright holder for this

doi: 10.1007/978-1-4939-7128-2_20. PubMed PMID: 28643264.

83. Ren X, Holsteens K, Li H, Sun J, Zhang Y, Liu LP, et al. Genome editing in Drosophila melanogaster: from basic genome engineering to the multipurpose CRISPR-Cas9 system. Sci China Life Sci. 2017;60(5):476-89. Epub 2017/05/21. doi: 10.1007/s11427-017-9029-9. PubMed PMID: 28527116. 
Fig 1. Verification of pNEX3-apATRPR and apATRPR genes, and B1/B2 neurons expressing the receptor apATRPR. (A) Gel electrophoresis of the plasmid pNEX3-apATRPR (approximately $4274 \mathrm{bp}$ ) and apATRPR gene (approximately $1215 \mathrm{bp}$ ) digested from the BamHI-KpnI restriction fragment of pNEX3 (approximately 3059 bp). apATRPR gene has been verified by sequencing. Lane 1: plasmid pNEX3-apATRPR; lane 2: apATRPR gene (the lower band) and pNEX3 vector (the upper band); M: marker. (B) The caudal surface of a buccal ganglion viewed with a regular light source. B1/B2 and other neurons on the left side were microinjected with plasmids pNEX3apATRPR and pNEX3-EGFP, and B1/B2 and other neurons on the right side were microinjected with only plasmid pNEX3-EGFP. Arrows and arrowheads: cells with successful injection (fast green). (C) B1/B2 neurons on both sides showed bright fluorescent green (arrows) under a fluorescence microscope. The left B1/B2 neuron expressed apATRPR and EGFP, and the right B1/B2 neuron expressed EGFP. Other neurons marked with arrowheads in (B) did not express injected genes. (D-E) A magnified view of the injected neurons in (C) showing left B1/B2 neuron (D) and right B1/B2 neuron (E). Scale bars in B and C: $500 \mu \mathrm{m}$ (scale bar in C is for B and C); Scale bars in D and E: $200 \mu \mathrm{m}$ (scale bar in E is for D and E). EN: esophageal nerve; BN1: buccal nerve 1; BN3: buccal nerve 3; RN: radular nerve.

Fig 2. apATRP enhanced B8 excitability but not B1/B2 excitability. (A-B) apATRP increased B8 excitability at $10^{-5} \mathrm{M}$ but not at $10^{-6} \mathrm{M}$. (A) A representative example. (B) Group data. Bonferroni post hoc tests: $*(\mathrm{p}<0.05), * *(\mathrm{p}<0.01)$. Error bars, SE. (C-D) apATRP had no significant effect on B1/B2 excitability. (C) A representative example. (D) Group data. Bars in A and C denote current injections. Recordings in (A, C) were made in high divalent saline. 
Fig 3. apATRP increased the excitability of B1/B2 neurons that expressed the receptor

apATRPR. (A-B) At $10^{-6} \mathrm{M}$ and $10^{-5} \mathrm{M}$, apATRP increased B1/B2 excitability, which expressed the receptor apATRPR. (A) Representative example. (B) Group data. Bonferroni post hoc tests: *** (p < 0.001). Error bars, SE. (C-D) apATRP had no significant effects on B1/B2 neurons that do not express the receptor apATRPR. (C) A representative example. (D) Group data. Recordings in (A, C) were made in high divalent saline. Bars in $\mathrm{A}$ and $\mathrm{C}$ denote current injections in B1/B2. 


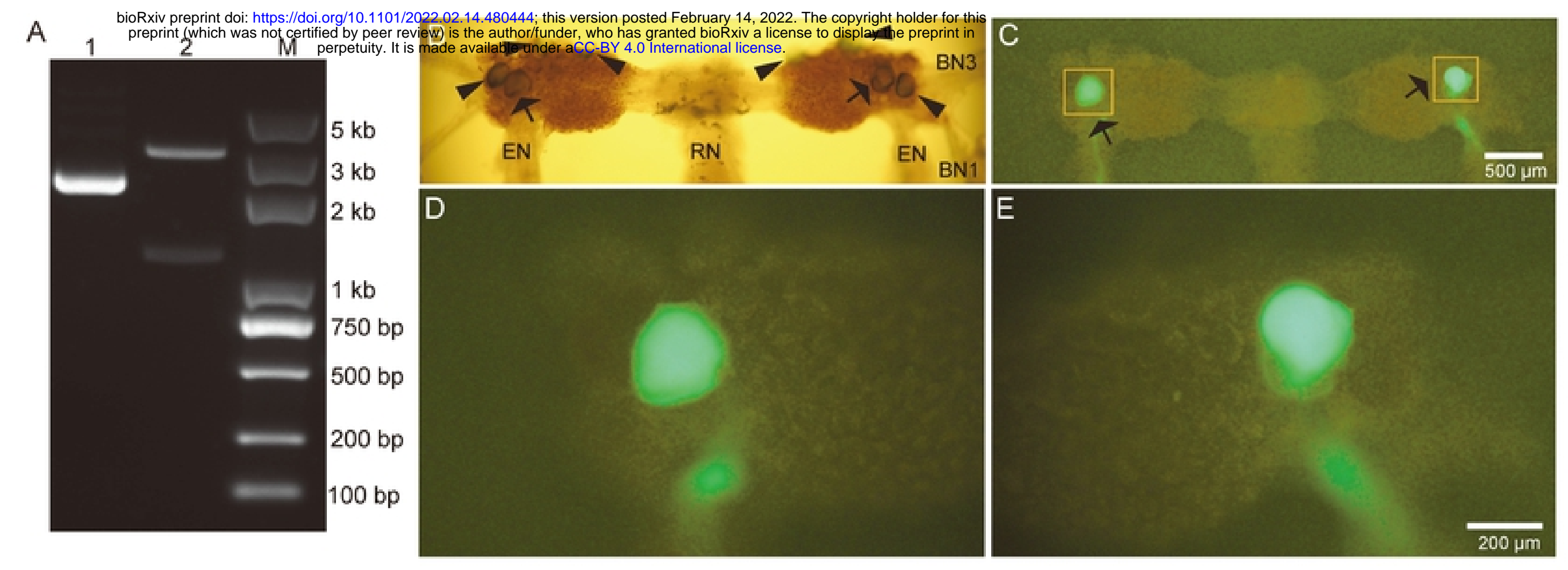

Figure 1 
A Control $10^{-6} \mathrm{M}$ apATRP

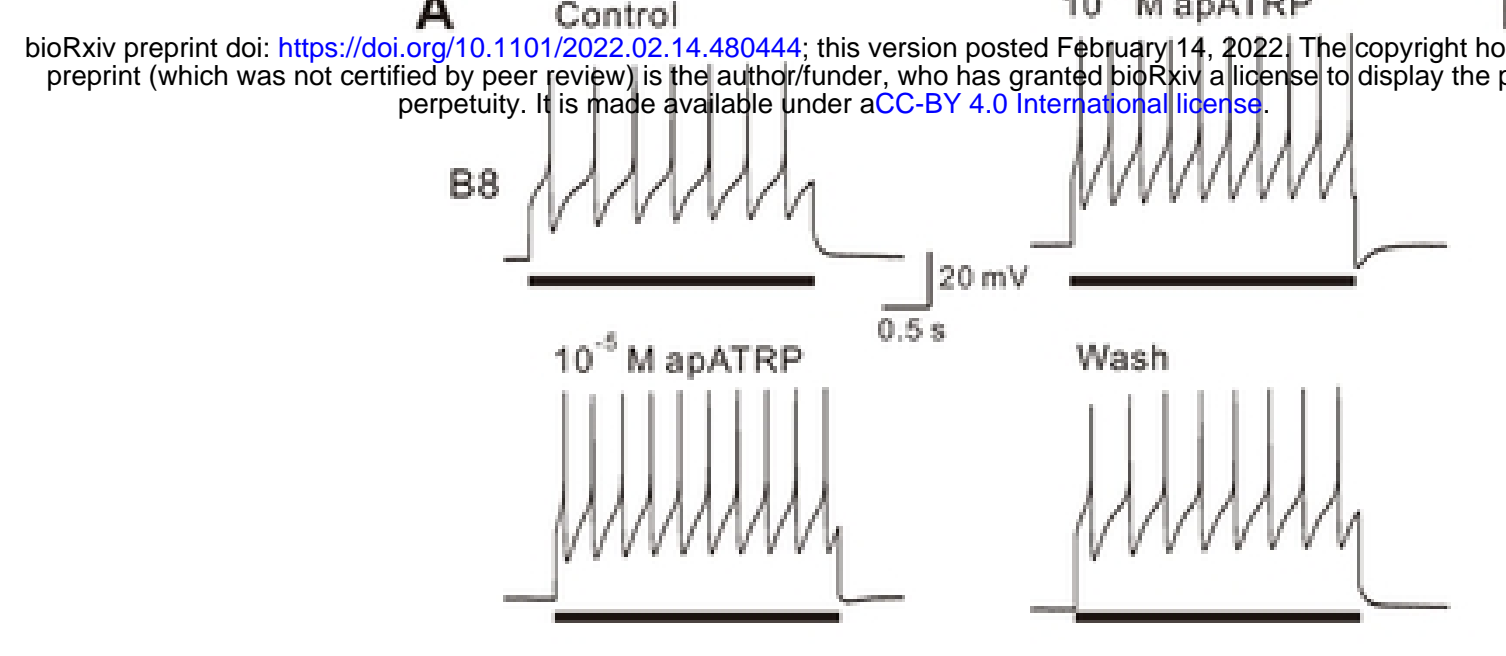

der forpthis

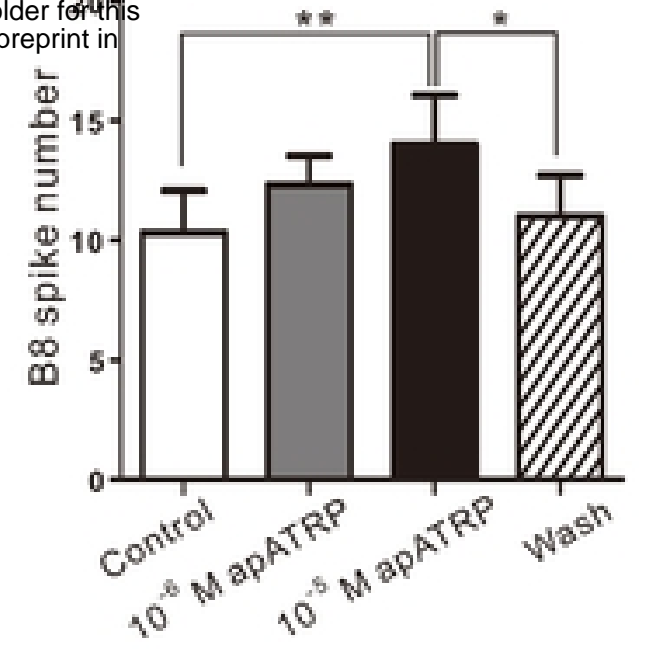

C
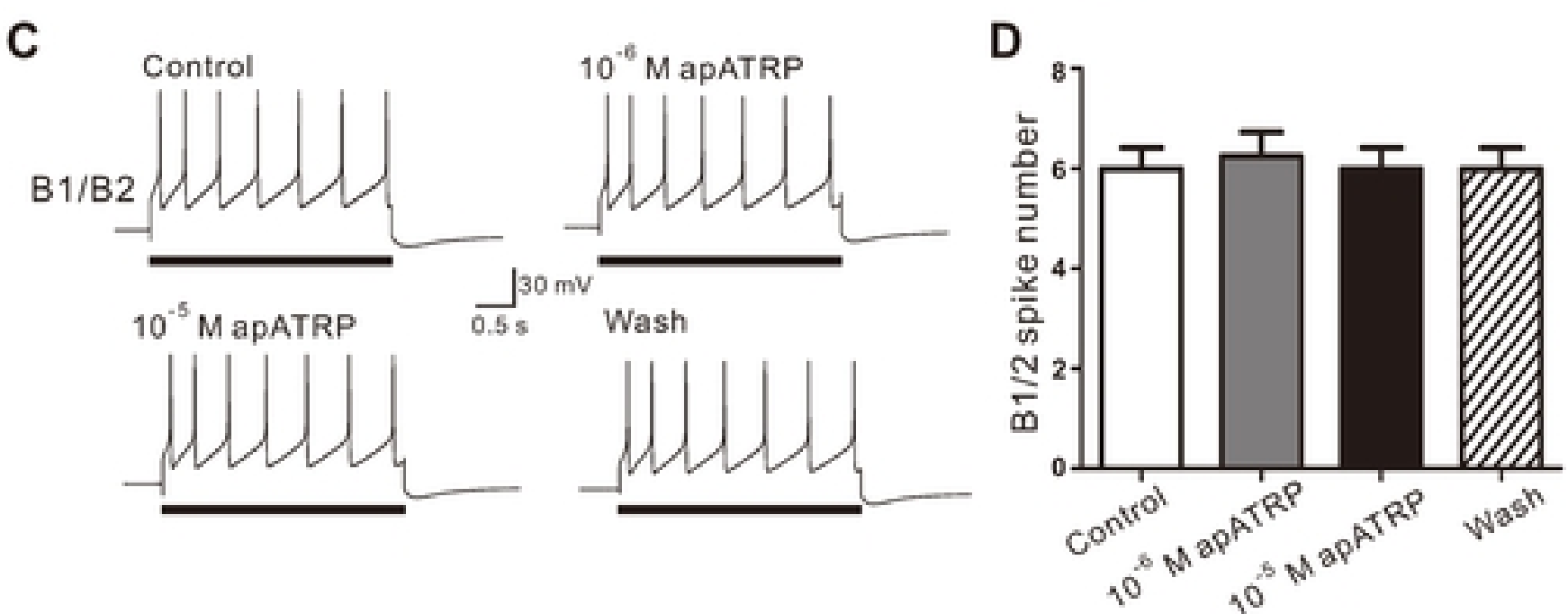

Figure 2 
bioRxiv preprint doi: https://doi.org/10.1101/2022.02.14.480444; this version posted February 14, 2022. The copyright holder for this perpetuity. Itris made available under aCC-BY 4 . I International license.
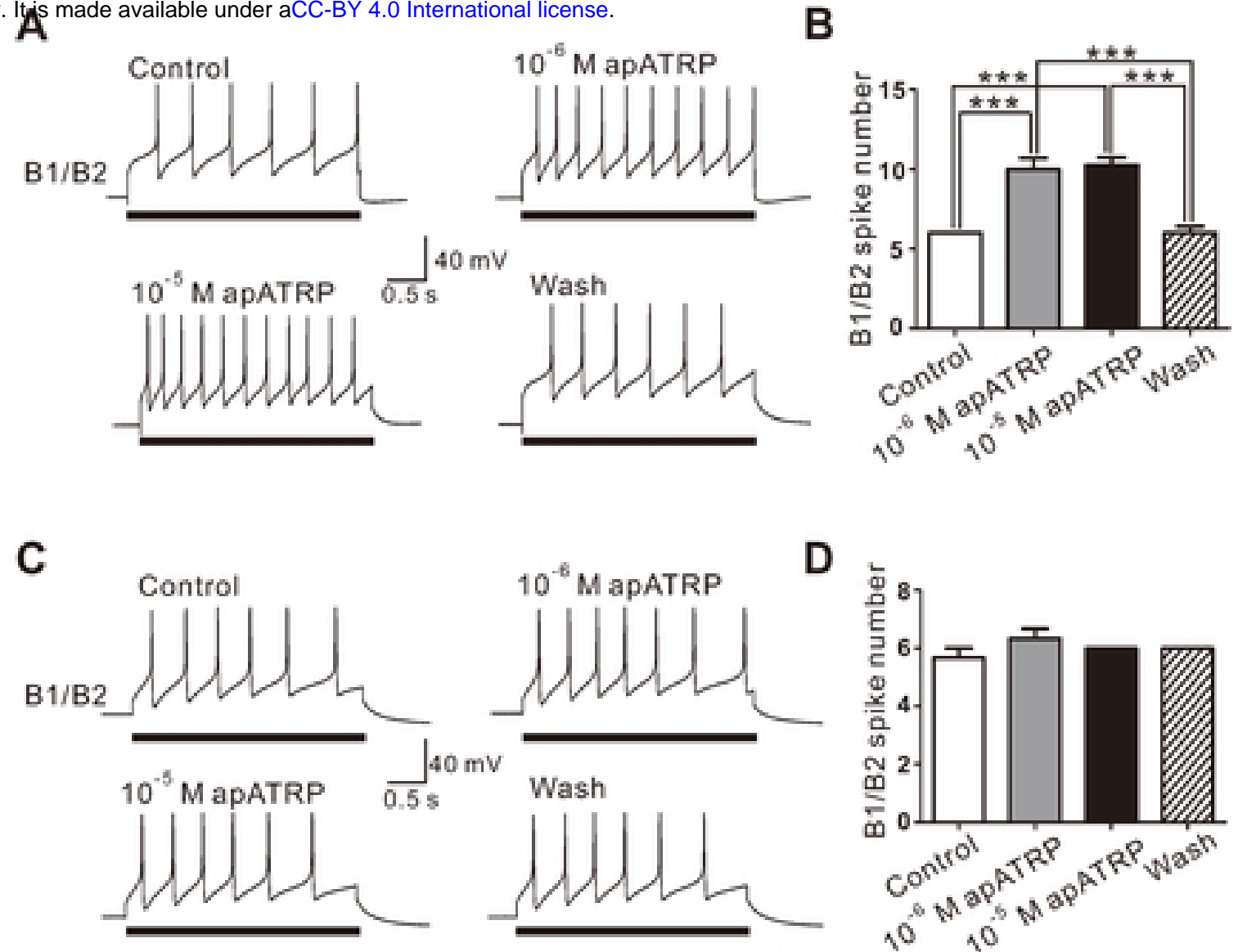

Figure 3 